УДК 339.727.2

\title{
И. И. Слатвицкая
}

Институт сферы обслуживания и предпринимательства (филиал) ДГТУ, Шахты, e-mail: Sii-64@mail.ru

\section{Е. В. Шериова}

Институт сферы обслуживания и предпринимательства (филиал) ДГТУ, Шахты, e-mail: katrina-2000@list.ru

\section{К ВОПРОСУ О ПРИВЛЕЧЕНИИ ИНОСТРАННЫХ ИНВЕСТИЦИЙ В ЭКОНОМИКУ РОССИИ}

Ключевые слова: иностранные инвестиции, прямые иностранные инвестиции, инвестиционный климат, инвестиционная привлекательность, зарубежный капитал.

Данная статья посвящена проблемам привлечения иностранных инвестиций в экономику России. Рассматривается динамика прямых иностранных инвестиций, на основании которой проводится анализ объема входящих в Россию и исходящих из нее инвестиций, а также дается характеристика движению иностранного капитала в стране и выявляются основные факторы, определяющие уровень инвестиций из зарубежных стран в Россию в конкретный промежуток времени. Дается оценка состоянию инвестиционного климата Российской Федерации. Особое внимание уделяется проблемам, сдерживающим рост зарубежных вложений в отечественную экономику, приводятся соответствующие примеры, раскрывающие недостатки инвестиционного климата страны. Новизна данного исследования заключается в том, что были проанализированы способы, способствующие повышению инвестиционной привлекательности России для иностранных инвесторов, а также были приведены мероприятия, которые уже активно реализуются и способствуют улучшению инвестиционного климата в Российской Федерации.

\section{I. Slatvitskaya}

The Institute of the Service Sector and Entrepreneurship (Branch) of «Don State Technical University» in Shakhty, e-mail: Sii-64@mail.ru

\section{E. V. Shershova}

The Institute of the Service Sector and Entrepreneurship (Branch) of «Don State Technical University» in Shakhty, e-mail: katrina-2000@list.ru

\section{TO THE QUESTION OF ATTRACTING FOREIGN INVESTMENTS IN THE RUSSIAN ECONOMY}

Keywords: foreign investment, foreign direct investment, investment climate, investment attractiveness, foreign capital.

This article is devoted to the problems of attracting foreign investment in the Russian economy. The dynamics of foreign direct investment is considered, on the basis of which an analysis is made of the volume of investments entering and leaving Russia, as well as a description of the movement of foreign capital in the country and the main factors that determine the level of investment from foreign countries to Russia in a specific period of time are revealed. The state of the investment climate of the Russian Federation is assessed. Particular attention is paid to the problems restraining the growth of foreign investments in the domestic economy, relevant examples are given that reveal the shortcomings of the country's investment climate. The novelty of this study lies in the fact that it analyzed methods that contribute to increasing the investment attractiveness of Russia for foreign investors, as well as measures that are already being actively implemented and contribute to improving the investment climate in the Russian Federation.

\section{Введение}

На сегодняшний день в условиях усиления процессов глобализации вопрос о привлечение иностранных инвестиций в российскую экономику является довольно актуальным. Учитывая, что

государству необходимо проводить процесс модернизации, активировать инновационную деятельность и достигать высоких показателей экономического развития, поступление зарубежного капитала в Россию необходимо. 
Привлечение иностранного капитала относится к одному из главных стратегических направлений передового экономического развития России. Ключевая роль в данном процессе отводится прямым иностранным инвестициям (ПИИ), которые позволяют усовершенствовать технологические процессы, дают доступ к инновационным разработкам и содействуют росту конкурентоспособности экономики.

\section{Цель исследования}

Целью исследования является анализ текущего состояния инвестиционного климата России, выявление проблем, сдерживающих рост иностранных вложений в российские проекты, а также предложение мер, способствующих повышению инвестиционной привлекательности Российской Федерации.

\section{Материал и методы исследования}

В ходе подготовки данной работы были задействованы эмпирические методы исследования, а именно изучение источников информации, касающихся иностранного инвестирования, в процессе подготовки материала внимание обращалось на публикации современных авторов по проблемам улучшения инвестиционного климата. Кроме того в статье применяются общенаучные методы исследования в рамках сравнительного, логического и статистического анализа, а также посредством анализа статистических данных, представленных Центральным банком Российской Федерации, сравнения динамики объема иностранных инвестиций в России по годам, обобщения полученного материала и графической интерпретации данных.

\section{Результаты исследования и их обсуждение}

Согласно статистике, приведенной Центральным банком Российской Федерации, за первый и второй квартал 2019 года поступление прямых иностранных инвестиций в экономику Российской Федерации составило 16,52 млрд долл. Так по итогам данного временного промежутка наблюдается рост ПИИ в экономику России, а также замедление оттока капиталов за границу.

Увеличение объема иностранных инвестиций в отечественную экономику в 2019 году отмечается после их резкого падения в 2018 году. За аналогичный промежуток 2018 года приток зарубежного капитала превысил 10,15 млрд долл., однако во втором полугодие наблюдался отток ПИИ, что привело к общему их снижению до 8,82 млрд долл. по итогам данного года. Тем не менее, величина исходящих из России инвестиций в 2018 году осталась на довольно высоком уровне и превысила величину входящих инвестиций более чем в 3,6 раза [8].

В 2018 году по данным Банка России отток капитала из отечественных организаций составил 6,46 млрд, это максимальный показатель с 1997 года. Статистика, опубликованная Банком России, показывает более чем трехкратное снижение входящих потоков зарубежных вложений за 2018 год, если сопоставить с объемом 2017 года - 8,8 млрд долл. против 28,6 млрд долл. (рисунок).

Возможными причинами, послужившими сокращению зарубежных вложений в Россию и оттоку капитала в 2018 году, являются имеющиеся геополитические риски, ситуация с возросшими угрозами расширения санкций в отношении Российской Федерации и незначительный экономический рост.

Росту зарубежных вложений в отечественную экономику в 2019 году поспособствовала существующая в данный момент довольно нейтральная геополитическая обстановка, отсутствие прямых внутренних и внешних конфликтов, а также снижение актуальности санкционных рисков. Кроме того, увеличение иностранных инвестиций в 2019 году эксперты «НГ» связывают с возможным переделом сфер влияния и интересов крупнейших мировых инвесторов на фоне торгового конфликта США с Китаем [4].

Однако существенных улучшений, которые бы способствовали повышению объема ПИИ в страну, пока не наблюдается. Текущее состояние инвестиционного климата в России нельзя назвать отличным, оно оценивается как «не вполне удовлетворительное». Это означает, что, несмотря на такие положительные характеристики инвестиционного климата Российской Федерации, как развитая деятельность в отраслях тяжёлой промышленности (металлургии, машиностроения, химической и нефтедобывающей), 
большая концентрация трудовых ресурсов и значительные объемы природных ресурсов, в стране существует ряд проблем, которые делают ее не самой привлекательной страной для вложения иностранных инвестиций.

Так одной из проблем иностранного инвестирования в российскую экономику является высокий уровень коррупции и экономической преступности в стране. Согласно данным отчета МВД РФ, в январе - сентябре 2019 года подразделениями органов внутренних дел выявлено 75,8 тыс. преступлений экономической направленности, за 8 месяцев 2019 года в стране совершилось 18,4 тыс. коррупционных преступлений, из которых 5,5 тыс. - это правонарушения в крупном и особо крупном размере. Совокупный ущерб по завершенным уголовным делам данной категории составил около 102 миллиардов рублей [5].

Следующей проблемой, сдерживающей рост иностранных инвестиций в российские проекты, является высокий уровень бюрократии, мешающий компаниям начать работать после получения статуса резидента. Так, например, из более 80 зарубежных компаний, зарегистрированных в экономических зонах Дальнего Востока, работают только 17 [7].

Существует проблема, связанная с недостаточной развитостью законода- тельства в области иностранного инвестирования. Большое число нормативных актов (указов, распоряжений, инструкций), регулирующих одни и те же правоотношения, зачастую противоречат друг другу. Помимо этого, отсутствует чёткая процедура предоставления гарантий и льгот иностранным инвесторам. Также наблюдается нестабильность в российском законодательстве, так как частое изменение законов, касающихся вопросов инвестирования иностранного капитала, приводит к усложнению его ввода на территорию страны. Так в 2018 году беспокойство инвесторов вызвало возможное введение закона, который запретил бы иностранцам работать с определенными российскими компаниями в определенных секторах. Этот закон не продвинулся, но создал негативное впечатление у иностранцев [6].

Еще один фактор, мешающий привлечению ПИИ в Россию, заключается в уровне налоговой нагрузки на иностранные компании. Дивиденды, получаемые заграничными инвесторами, облагаются налогом по более высокой ставке $(15 \%)$, чем доходы российских инвесторов (13\%). К тому же, существенной проблемой является нестабильность обстановки из-за рисков, сопряженных с непредвиденностью санкций, вводимых отдельными государствами.

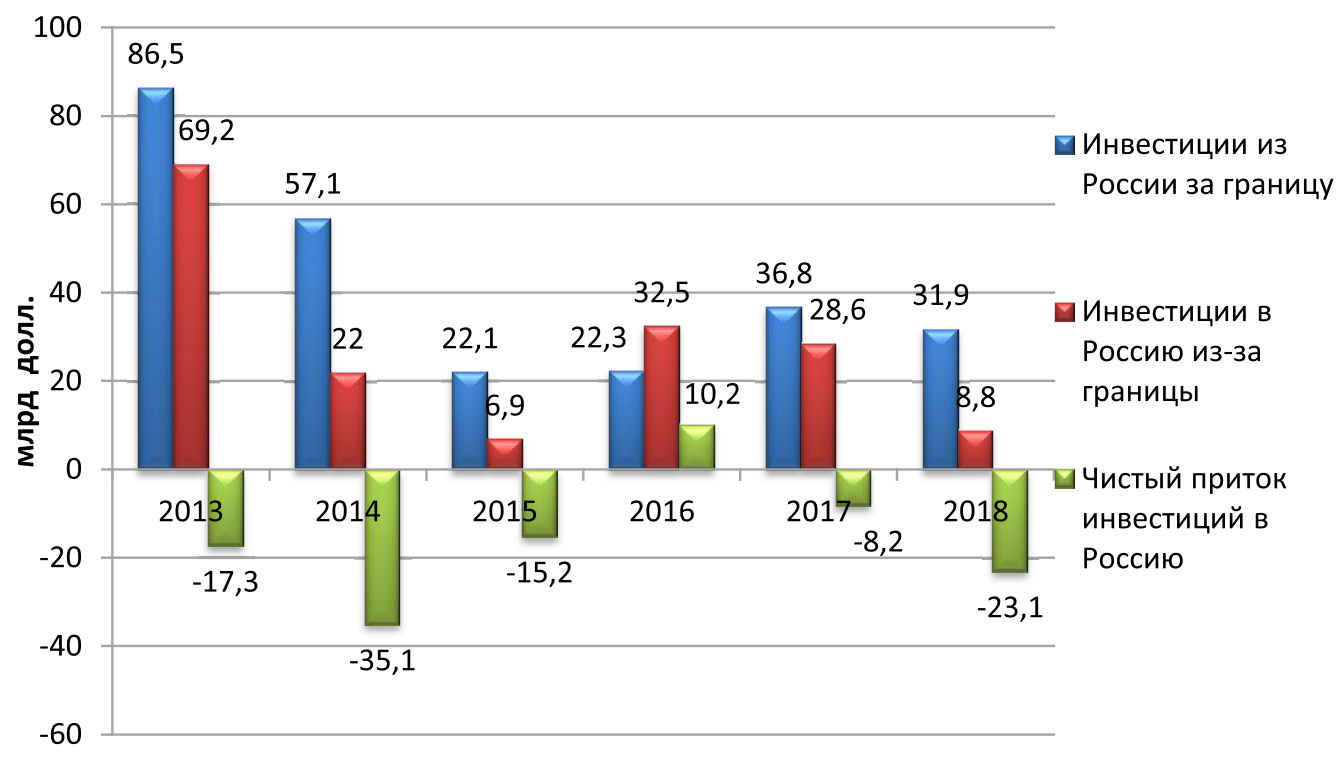

Динамика иностранных инвестиичий [3] 
К ряду проблем можно отнести и неполноценный учет региональных факторов и условий, который является одной из основных причин низкой плодотворности. Иностранные инвесторы из-за отсутствия достаточной информации о разных регионах предпочитают инвестировать в крупнейшие города России. Помимо этого, существенный интерес зарубежных инвесторов к определенным важным секторам отечественной экономики (к примеру, к электроэнергетике) сдерживается имеющимся в них государственным регулированием стоимости на продукцию [2].

В российской экономике существует достаточно проблем, мешающих росту привлечения иностранного капитала в страну, но также есть большой потенциал, чтобы решить все сложности и повысить свою инвестиционную привлекательность. Чтобы добиться существенного качественного увеличения зарубежных инвестиций в экономику России следует обратить внимание на меры, направленные на улучшение инвестиционного климата.

Для улучшения состояния инвестиционной среды необходимо снизить административную нагрузку за счет сокращения бюрократических процедур, усовершенствовать действующую систему льгот для иностранных инвесторов в отдельных отраслях и регионах. Особое внимание необходимо уделить страхованию рисков инвесторов, относящихся к потере имущества и капитала. Также требуется создание стабильного экономического и внешнеторгового законодательства, принятие мер по повышению прозрачности и эффективности законодательства за счет создания предсказуемых правил игры для всех участников рынка, следует устранить противоречивость и дублирование основных нормативных актов.

Требуется проводить активную борьбу с коррупцией. Для сокращения масштабов коррупции можно ограничить возможности вмешательства чиновников в хозяйственные процессы. Следует выработать определенные государственные программы, предотвращающие преступность в криминогенных сферах экономики для того, чтобы обеспечить безопасность деятельности иностранных инвесторов на территории страны.
Для того, чтобы создать доступ для иностранных инвесторов к информации об инвестиционных возможностях отечественной экономики и экономики регионов следует проводить в сжатые сроки и на постоянной основе мониторинг инвестиционного климата в регионах России.

Помимо этого, большое значение для продвижения зарубежного капитала отводится совместной работе России с ведущими международными финансовыми организациями, такими как Международный валютный фонд, Международный банк реконструкции и развития и другие.

Определенные преобразования, способствующие повышению уровня инвестиционной привлекательности Российской Федерации, уже реализуются. Так в данный период времени активно формируется организация взаимосвязи между регионами, российским центром содействия иностранным инвестициям (РЦСИИ) и зарубежным бюро РЦСИИ, которая проводит презентации для возможных иностранных инвесторов, распространяет публикации в различных изданиях и на разных интернет источниках, отражающих инвестиционную привлекательность России.

Также в целях улучшения инвестиционного климата в Российской Федерации действуют следующие организации: агентство стратегических инициатив; консультативный совет по иностранным инвестициям; институт федерального инвестиционного уполномоченного (инвестиционный омбудсмен). Министерство экономического развития России выполняет функции аппарата омбудсмена.

Вводятся специальные мероприятия «Трансформации делового климата». Этот план направлен на улучшение инвестиционного климата, упрощение ведения предпринимательской и инвестиционной деятельности в различных сферах экономики.

Продолжается работа по разработке законодательных инициатив в области иностранного инвестирования. Так, например, Минэкономразвития разработал законопроект «Об инвестиционных режимах и мерах стимулирования привлечения инвестиций в экономику Российской Федерации». 


\section{Выводы (заключение)}

Таким образом, в отечественной экономике в настоящий момент времени заметен прирост прямых иностранных инвестиций, однако в абсолютных цифрах инвестирование из-за границы остается незначительным, а объем инвестиций исходящих из России превышает объем поступающих от иностранных инвесторов. Такая ситуация явно не удовлетворяет потребностям экономики страны. Необходимо выделить, что в России активно применяются меры по усовершенствование инвестиционного климата, но, всё же, этого недостаточно и поэтому данная проблем остается актуальна и требует кардинальных преобразований в сфере иностранного инвестирования, что способствовало бы качественному росту инвестиционной привлекательности страны.

\section{Библиографический список}

1. Захарова А.А., Слатвицкая И.И. Инвестиционный климат России: проблемы и перспективы // Современные проблемы и перспективные направления инновационного развития науки: Сборник статей международной научно-практической конференции: в 8 частях. 2016. С. 178-181.

2. Черкесова Э.Ю., Миронова Д.Д. Институциональные инструменты реализации рационального импортозамещения в Российской Федерации // Экономика и предпринимательство. 2018. № 3 (92). С. 587-591.

3. Аналитики ЦБ объяснили трехкратный обвал иностранных инвестиций в Россию [Электронный ресурc]. URL: https://www.rbc.ru/economics/13/05/2019/5cd981989a7947252f589b47 (дата обращения: 30.11.2019).

4. Иностранные капиталы возвращаются в РФ [Электронный ресурс]. Режим доступа: http:// www.ng.ru/economics/2019-10-29/1_7714_capital.html (дата обращения: 23.11.19).

5. МВД оценило ущерб от коррупции в России [Электронный ресурс]. URL: https://www.newsru. com/russia/18nov2019/corruptstatmvd.html (дата обращения: 24.11.2019).

6. Почему зарубежные инвесторы боятся вкладывать деньги в Россию [Электронный ресурс]. URL: https:/quote.rbc.ru/news/article/5da9b4999a7947a1331801d8 (дата обращения: 30.11.2019).

7. Слишком Дальний: иностранные инвесторы не спешат вкладывать в ДФО [Электронный pecypc]. URL: https://iz.ru/922008/roza-almakunova/slishkom-dalnii-inostrannye-investory-ne-speshatvkladyvat-v-dfo (дата обращения: 30.11.2019).

8. Статистические данные Банка России [Электронный ресурс]. Режим доступа: https://www.cbr. ru/statistics/macro_itm/svs/\#CheckedItem (дата обращения: 23.11.19). 